\title{
NUESTRA PRESENCIA AÉREA, MARCó LA DIFERENCIA EN LA RECUPERACIÓN DE MITÚ
}

\author{
Crónica del General (RA) ÉDGAR A. LESMES ABAD
}

La Operación Vuelo de Ángel (O.V.A) como se le conoce a la recuperación de Mitú por parte de las Fuerzas Militares de Colombia, en cabeza de la Fuerza Aérea Colombiana (FAC), fue una operación que alteró la dinámica del conflicto armado colombiano, considerándose un hito en desarrollo de las operaciones contra la organización ilegal FARC y en favor del Estado. El poder aéreo fue factor decisivo durante la O.V.A ya que se potencializaron las capacidades aéreas que tenía la FAC y con ello se cambió favorablemente la correlación de fuerzas.

La operación se convirtió en un precedente doctrinal y operacional, ya que mediante las lecciones aprendidas se produjo una evolución de la Doctrina y las capacidades operacionales. La tecnología de los visores nocturnos, el sistema FLIR (infrarrojo) y la experiencia operacional de los pilotos fueron determinantes para modificar la estrategia armada de las FARC, quienes se encontraban para el año 1998 en una guerra de posiciones pero gracias al poder aéreo de la FAC regresaron a la guerra de guerrillas. Así pues, Mitú fue la última población que las FARC intentaron tomar y establecerse.

En la década de los años noventa, particularmente desde 1996, las FF.MM sufrieron duros golpes, sobre todo contra el Ejército Nacional. Ejemplo de esto fueron las Delicias, la Carpa, Patascoy, el Billar, Miraflores, etc. Estas acciones violentas generaron un efecto político-militar negativo contra el Estado y la población civil, por la utilización indiscriminada de armamento no convencional que iba dirigido contra unidades militares y policiales, afectando de manera sustancial a la población civil inerme y ajena al conflicto. Dichos ataques forjaron un sentimiento de victoria en los miembros de las FARC porque la toma de pueblos y la consecución de la estrategia armada estaba generando resultados positivos para la organización ilegal.

"Los ataques a las Delicias, el Billar, la Toma de Miraflores y la Toma de Mitú, demostraron la debilidad estatal y constituyeron duros golpes a las FF.MM. Estos

Ex comandante de la Fuerza Aérea Colombiana, Jefe de Operaciones de la Fuerza Aérea Colombiana cuando sucedió la Toma de Mitú el 1 de noviembre de 1998. 
ataques correspondieron a una estrategia política y armada de la guerrilla para consolidar su poder territorial en el sur del país, con el propósito de crear un corredor estratégico de movilidad hacia las fronteras con Brasil y Venezuela. Sin embargo, con la respuesta de las FF.MM. en cabeza de la Fuerza Aérea bajo la Operación Vuelo de Ángel, se logró frenar la estrategia armada de la organización ilegal.' (MARín et al, 2017).

Los ataques llevados a cabo por las FARC contra la población civil y las FF.MM, evidenciaron además la debilidad y la incapacidad institucional del Estado para hacerle frente y contrarrestarlos.

"Las FARC entre 1996 y 1998 en zonas del Sur del país demostraron que aprendieron a luchar con un entorno adverso e incierto. Así mismo, pusieron a prueba su capacidad de maniobra, libertad y rapidez de acción. Entre los cambios más significativos observados en la dinámica del conflicto se destaca también la manifiesta prioridad que las FARC dieron entre 1997 y 2001 a los ataques a las poblaciones para destruir los puestos de Policía y debilitar la presencia estatal en los sitios donde buscaban ampliar su influencia." (CASTILla, 2004).

La pérdida de la iniciativa estratégica y operacional del Estado Colombiano entre los años 1994 y 1998 estuvo ligada a las malas relaciones entre el poder Ejecutivo y la Institución militar. Mientras el país requería con urgencia de una estrategia para la seguridad y la defensa, el gobierno se dedicaba a defenderse de los señalamientos de escándalos de corrupción, ilegitimidad, incapacidad gubernamental y el más grave, financiación ilícita de la campaña presidencial con dineros del narcotráfico.

"Para cualquier República contemporánea, el balance de poder entre las autoridades civiles y el estamento militar es un factor crucial, pues tiene incidencia directa sobre la forma del régimen político, el modelo de desarrollo, la relación del Estado con la ciudadanía e incluso sobre las relaciones internacionales". (BECERRA, 2016).

De otra parte, las relaciones exteriores con los Estados Unidos llegaron al nivel más bajo, Colombia fue desertificada, situación que afectó a los militares colombianos en la medida en que la ayuda militar disminuyó notoriamente de 96 millones de dólares en 1994 a 51 millones en 1995 (LoBE, 1998).

"La crisis moral y política del gobierno le resta legitimidad para imponer las condiciones a los militares y ofrecer suficientes garantías para el desarrollo de las negociaciones. La relación de tensión con los Estados Unidos en torno a la extradición de nacionales y las investigaciones adelantadas por la fiscalía a miembros de la campaña y del partido oficialista, derivó en una coyuntura de crisis política y baja credibilidad en el gobierno de turno.” (Lopez, 1999, p. 12).

Para esa época la Fuerza Aérea operaba con recursos y equipos que eran escasos y obsoletos, la inversión en el gasto de seguridad y defensa para el período de 1994-1998 según lo señala el Departamento Nacional de Planeación: 
“...la distribución prevista para inversión en el período se dio prelación a los programas de mantenimiento mayor y adquisición de material y equipo complementario, buscando el mayor grado de alistamiento y operatividad de lo existente, en lugar de la adquisición de nuevos equipos con tecnología de punta. Consecuentemente, el actual Gobierno no emprendió mega proyectos militares de inversión." (DNP, 1991).

De esta manera se evidencia que para esos años la inversión en el gasto de seguridad y defensa no fue la adecuada pese a las amenazas que representaban los grupos armados ilegales.

Teniendo en cuenta el escenario de seguridad de la década de los años noventa en Colombia se puede afirmar que este país no ha sido militarista, es decir, que históricamente no se ha invertido mucho en el gasto de seguridad y defensa como se puede ver reflejado en los años 1994-1996, donde el presupuesto al sector no superó $3 \%$ del PIB.

Para el funcionamiento o la puesta en marcha de operaciones los recursos eran escasos, faltaba liderazgo político y las herramientas militares que se tenían, así como el equipo aéreo no era suficiente para contener la amenaza que representaron los grupos armados ilegales como las FARC.

Por otro lado, había un gran desconocimiento del poder civil sobre la capacidad militar, especialmente sobre el poder aéreo que era la gran ventaja que tenía el Estado sobre dichos grupos. En gran parte se debe eso a la demora en aplicar la fuerza efectivamente.

Con el gobierno de Andrés Pastrana la situación cambió, el mandatario reunió a la cúpula en Cartagena con el fin de analizar la situación de orden público del país y conocer la capacidad militar y los medios que se disponían para enfrentar la amenaza.

En dicha reunión se le explicó al señor Presidente que el presupuesto era escaso y faltaban medios. Para el caso de la Fuerza Aérea se le manifestó que las aeronaves de ala rotatoria, de transporte y de combate del inventario aeronáutico eran insuficientes y obsoletas para la amenaza que se estaba enfrentando, faltaban recursos adecuados para operar eficiente y efectivamente, esa era la situación que se vivía en esa época.

De esa reunión salió la iniciativa del Plan Colombia, algo parecido, guardadas proporciones al Plan Marshall de los Estados Unidos en Europa después de la Segunda Guerra Mundial.

El Plan Colombia fue una política exterior que logró articular la Estrategia Política del Estado con la Estrategia Militar. Con esta articulación las relaciones cívico militares entre el Ejecutivo y la Fuerza Pública mejoraron significativamente y el Plan permitió la consecución de recursos y medios para operar. 
El apoyo de los Estados Unidos de Norteamérica mediante el Plan Colombia propició un proceso de reingeniería y reestructuración de las FFMM, adecuándolas para la guerra irregular. Además, se fortaleció la inteligencia tecnológica, especialmente satelital.

El Presidente Andrés Pastrana se había comprometido con las FARC a realizar la paz, despejando algunas zonas en los departamentos de Caquetá y Meta que comúnmente se le conoció como la zona de distensión. Dentro de las exigencias que hicieron las FARC, solicitaron al Presidente de la República el despeje del Batallón Cazadores en San Vicente del Caguán. Para las FFMM esta decisión fue difícil porque para nosotros era ceder y perder una unidad militar y todo lo que ella representaba.

\title{
La OPeración Vuelo de Ángel
}

Para la década de los años noventa las FARC venían implementando la llamada guerra popular prolongada, la cual consistía en tres etapas, estas son: Guerra de guerrillas, guerra de movimientos y guerra de posiciones.

\begin{abstract}
"Para 1996 las FARC ya se encontraban en la etapa de guerra de movimientos, los ataques perpetrados durante este año y hasta 1998, son el reflejo del paso de la guerra de guerrillas a la guerra de movimientos. Esto se debe a la estrategia armada de la guerrilla de propiciar golpes a unidades militares, durante un tiempo prolongado, con armamento pesado y utilizando una cantidad alta de combatientes. Así dejan las emboscadas, y los ataques de repliegue, para pasar a un enfrentamiento prolongado con las Fuerzas Militares. Los ataques a las Delicias, El Billar, Miraflores reflejan precisamente ese cambio de estrategia." (MARÍn et al, 2017).
\end{abstract}

El primero de noviembre de 1998 cuando inicia la toma de Mitú, yo era el Jefe de Operaciones de la Fuerza Aérea, ese día había un evento deportivo con la Policía. A las 4 a.m. sonó el teléfono, era el Centro de Operaciones de la Fuerza Aérea, y se informó que estaban arremetiendo contra Mitú. Para esa época, con cierta frecuencia las FARC atacaban poblaciones pequeñas, la Fuerza Aérea reaccionaba y los guerrilleros huían al sentir la presencia de las aeronaves.

La Fuerza Aérea tiene prohibido emplear las armas sobre las poblaciones o cuando se presume que hay personal civil en el área, esto con el fin de evitar daños colaterales, o causar la muerte a personal inocente.

Geográficamente me ubiqué y pensé en Miraflores, y supuse que en Mitú iban a hacer lo mismo que habían hecho en Miraflores meses atrás, es decir, se estarían ahí por un tiempo prolongado. Mitú, capital de un departamento en poder de las FARC, sería una noticia muy favorable para la guerrilla y muy desfavorable para el Estado colombiano, su gobierno y Fuerza Pública. 
Cuando sucedió lo de Miraflores, sorprendió el factor sorpresa y la reacción de la Fuerza Pública fue débil, pero la FAC venía implementando su Doctrina Operacional, adquiriendo nuevos equipos, sobre todo nocturnos, ya existía la experiencia de Miraflores, por consiguiente, en Mitú la reacción de la Fuerza Aérea fue contundente.

En la Operación Vuelo de Ángel se utilizó el principio de Masa y Concentración de Medios, se utilizaron diversos tipos de aeronaves para cada una de las misiones asignadas, ala rotatoria y ala fija, y se aprovecharon todas las características de la Fuerza Aérea: velocidad, alcance, flexibilidad y versatilidad.

Todo esto permitió dar una respuesta muy rápida, con lo cual se sorprendió a las FARC. La capacidad tecnológica y operacional demostrada en Mitú permitió que la Fuerza Aérea potencializara sus aeronaves para frenar y contener los ataques de los grupos armados ilegales.

Sin temor a equivocarme, Mitú fue la última población que las FARC trataron de tomarse pues allí sufrieron una pérdida considerable de guerrilleros. Las FARC se vieron obligadas a regresar de la guerra de posiciones a la cual querían llegar a la guerra de guerrillas. Allí el Estado cambió la ecuación a su favor y las FARC que se consideraban victoriosos iniciaron su declive.

\section{Planeamiento de la OPeración}

Para iniciar el apoyo aéreo ordené la salida de dos aviones: Un AC -47 que se encontraba en CACOM 6 "Tres Esquinas", y una hora después otro AC-47 en CACOM 2- "Apiay".

Con los recursos disponibles de la aeronave AC-47 conocida como el "Fantasma", se realizó un primer apoyo aéreo a la Estación de Policía en Mitú. En ese momento, la inteligencia y la información operacional recibida era que las FARC se estaban tomando la capital del departamento del Vaupés.

A las 6 de la mañana, en el evento de la Policía con mi hija, y cuando ya iba a comenzar la maratón se me acercaron dos generales de la Policía entre ellos el General Alfredo Salgado, me dijeron que la situación en Mitú se estaba complicando.

Prácticamente, las FARC estaban copando la Policía, su intención era permanecer en la capital del departamento del Vaupés por un largo tiempo. Se calculó que la correlación de fuerzas era de 5 guerrilleros por 1 Policía, y estos tenían a su favor que disponían de toda el área de la población para maniobrar a su conveniencia, mientras la Policía se encontraba recluida en su cuartel a merced del diferente tipo de armamento de las FARC (granadas, fusiles, ametralladoras, cilindros, lanza cohetes). 
Igualmente, el objetivo fue bien seleccionado, puesto que se dificultaba el apoyo: las únicas vías de comunicación eran el río Vaupés, el cual se encontraba controlado por las FARC a varios días de navegación y la vía aérea.

En el caso de la pista aérea que es la calle principal de Mitú estaba bloqueada, y en cercanías no existía ninguna otra pista aérea que se pudiera utilizar. Me fui con los generales, para el Centro de Operaciones de la Policía, nos comunicamos con la Policía de Mitú y la situación era desesperante, ellos se defendían, pero no era mucho lo que podían hacer con los aviones la comunicación no era fluida por la distancia y la baja altura en la cual estaban operando. Ordené al Comandante del CACOM 2 que despegara un T- 27 Tucano para que se ubicara a la altura de San José del Guaviare y nos sirviera de repetidora con los AC-47 que se encontraban operando sobre Mitú.

En ese sentido, se estaba poniendo en práctica uno de los principios del poder aéreo, el Control Centralizado y la Ejecución Descentralizada, con el cual se debía tener comunicación permanente con todos los actores de la operación. Ya comunicados con la Policía y con los AC-47 que apoyaban donde podían, se tenía información completa sobre la ubicación de las FARC en la población, pero era poco lo que podían hacer pues estos se encontraban con las personas que eran utilizadas como escudos humanos.

Analizando que era inminente que iban a copar a la Policía, inicié un plan para recuperar Mitú, reuniendo las aeronaves que teníamos disponibles de ala fija y rotatoria para llevar tropa a Mitú en el menor tiempo posible.

Para poder realizar la operación se requería de una pista base aérea adelantada desde la cual pudieran operar los helicópteros despegando de San José del Guaviare para desembarcar la tropa y regresar para reaprovisionarse de combustible y llevar más tropa. La autonomía de los helicópteros no les alcanzaba para ir a Mitú o en cercanías y regresar a San José.

De esta manera se buscó en toda el área y no se encontró una pista que sirviera para nuestro propósito, la única pista que servía estaba en territorio de Brasil cerca de la frontera, Querari, un puesto militar del Ejército Brasilero. 


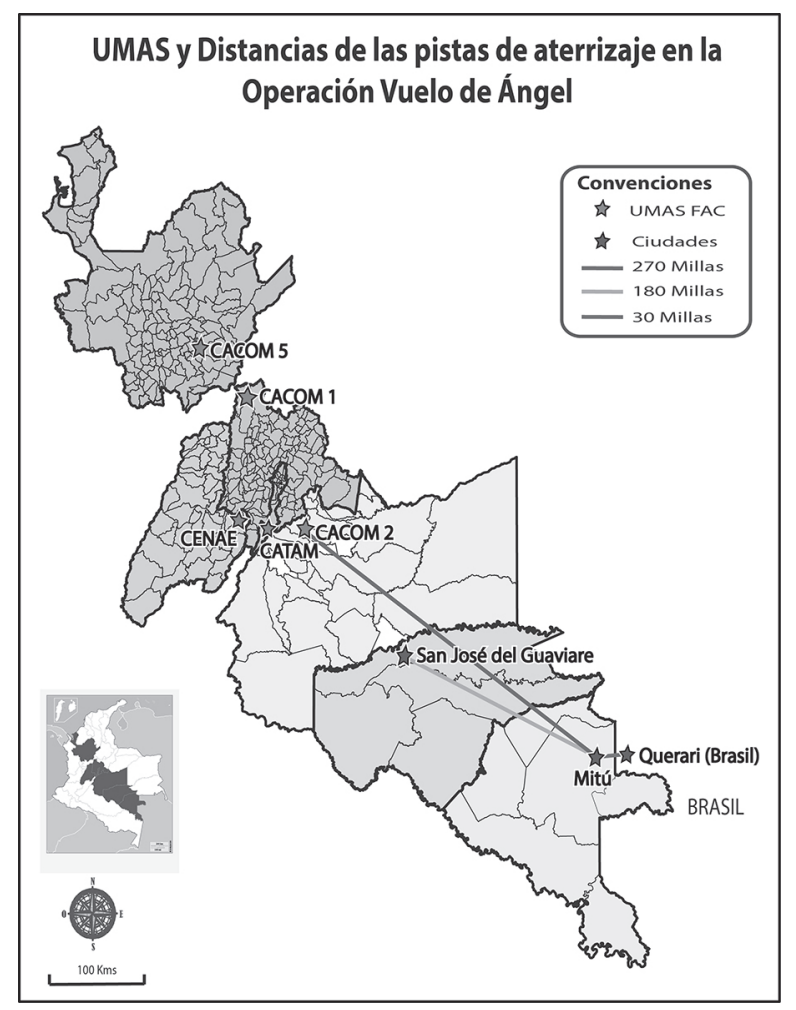

Mapa 1. UMAS y Distancias de las pistas de Aterrizaje en la Operación Vuelo de Ángel Fuente: (GARZÓN, 2018) $)^{2}$

Teniendo en cuenta que para retomar Mitú era imprescindible utilizar la pista de Querari en territorio del Brasil, había que tener autorización del hermano país. Ese primero de noviembre de 1998 era un día festivo en Colombia y también en el Brasil, a las 10:00 hrs aproximadamente hora de Colombia se procedió a llamar a la casa del Coronel Carlos Barrero F., quien era el Agregado de la Fuerza Aérea. Lamentablemente el Coronel Barrero estaba en vacaciones y no se encontraba en la casa. Llamé al suboficial de la Fuerza Aérea Adjunto a la Embajada y le informé de la gravedad de la situación que teníamos en Mitú, Colombia, nosotros requeríamos con urgencia que la Fuerza Aérea Brasilera nos autorizara para utilizar la pista de Querari como base aérea adelantada logística para transportar combustible armamento y tropa, para que desde allí se pudieran lanzar operaciones aéreas y recuperar Mitú.

2 Mapa elaborado por el investigador Daniel Garzón, miembro del grupo de investigación “Análisis en Contexto" registrado ante Colciencias. 
Dos horas más tarde, recibí una llamada del suboficial con la noticia de que la Fuerza Aérea del Brasil autorizaba la utilización de la pista de Querari para nuestras aeronaves de ala fija y rotatoria.

Mientras esto ocurría, se estaban alistando los aviones Hércules C-130 y C-235 para transportar combustible y tropa a Querari y San José del Guaviare, los helicópteros UH-60 Black Hawks para concentrarlos en la Base Aérea de Apiay y desde allí proceder a San José, y los T-27 y OV-10 con armamento para operar cuando las FARC iniciaran a salir de la población.

Por otro lado, el Comandante del Ejército ya se encontraba enterado de la situación y estaba alistando las tropas en Tolemaida y en Apiay para ser recogidas por las aeronaves de transporte y llevarlas a San José y Querari. El Coronel Director de Operaciones Aéreas se encontraba en el Centro de Operaciones de la Fuerza Aérea y yo en el Centro de Operaciones de la Policía, desde allí coordinábamos todo lo necesario con los Comandantes de los Comandos Aéreos comprometidos.

Hacia las 14:00 horas, recibí una llamada del suboficial de la Fuerza Aérea, informándome que la Fuerza Aérea del Brasil no autorizaba la utilización de la pista. Con esta contraorden se perjudicaba la operación, pero era la única opción que se tenía para poder llegar a Mitú. Ahora bien, tomé la decisión y se le dijo al suboficial que le informara a la Fuerza Aérea Brasilera que ya las aeronaves habían despegado para Querari y no tenía comunicación con ellas para hacerlas regresar.

En vista de este impase de última hora y en el cual estaba involucrado un país vecino y amigo, me comunique con el ministerio de Relaciones Exteriores y se le informó lo que se podía presentar. Los helicópteros ya se encontraban en San José y eran las 16:00 cuando despegaron con tropas para Querari.

El único que en ese momento disponía de visores nocturnos (NVG) era el líder, puesto que se estaba en el momento de transición hacia las operaciones nocturnas, y no se disponía de más.

Lo anterior, porque durante el gobierno del presidente Ernesto Samper, los Estados Unidos restringieron el suministro de equipos para la Fuerza Aérea. Los helicópteros debían aterrizar prácticamente de noche y debían guiarse por el líder que sí tenía visión nocturna, además el AC-47 los estaba esperando sobre la pista para iluminarla con el lanzamiento de bengalas (las cuales convertían la noche en día).

Posteriormente, los helicópteros llegaron a su destino con la tropa abordo sin novedad (todos sentimos un gran alivio y satisfacción pues la misión se estaba cumpliendo de acuerdo a lo planeado). La Fuerza Aérea estaba en proceso de modernización y adaptando su Doctrina a la nueva situación que se estaba viviendo porque era el momento de ser proactivos y dinámicos. 
El piloto del primer C-130 que aterrizó en Querari era el Coronel Alfredo González M, hoy Mayor General (r), él sobrevoló la pista y vio que no era una pista muy larga pero que no se era apta para el C-130. Sin embargo, debido a la premura del tiempo, tomó la decisión de aterrizar y gracias a su experiencia el aterrizaje fue exitoso, efectivamente la pista no estaba diseñada para ese tipo de aeronave y por el peso del avión se dañó una parte de la superficie en una de las cabeceras.

La tecnología que se estaba adquiriendo fue determinante para alterar la dinámica por parte de las FARC, el uso del FLIR para ubicar la guerrilla, las bengalas para facilitarle a las tropas su movilidad en la noche, los tiradores de alta precisión desde las aeronaves y los visores para la operación nocturna de los helicópteros, esto le permitió a la Fuerza Aérea operar 24 horas de día y noche facilitándole a las fuerzas de superficie su accionar en el terreno.

La guerra de guerrillas en la cual el enemigo operaba en pequeños grupos dispersos no ofrece objetivos lucrativos para el poder aéreo. En Mitú donde las FARC operaron en gran cantidad y trataron de pasar a la guerra de posiciones, quedaron expuestas al fuego del poder aéreo cuando la Fuerza Pública los obligó a desalojar Mitú, por eso la gran cantidad de bajas que sufrieron.

En Querari, estaba de noche ya teníamos tropa, helicópteros, combustible, para empezar al día siguiente el desembarco. Mientras tanto, el Avión Fantasma seguía sobrevolando el pueblo, mirando, observando y tratando de hacer lo que podían. La FAC tiene una norma y es que en áreas pobladas no se puede disparar. Para esa época, se diseñaron los famosos tiradores de plataforma (aeronave), estos son un grupo de francotiradores entrenados y equipados con fusiles .50 de alta precisión.

Como era imposible utilizar las armas dentro del poblado, se lanzaron bengalas, se utilizó el perifoneo en una operación psicológica para mantener a los guerrilleros despiertos y así estuvimos toda la noche.

Al día siguiente los helicópteros salieron con la tropa, ya se había seleccionado el área de desembarco que no podía ser dentro del pueblo porque estaban los guerrilleros. En las afueras del pueblo había unas áreas apropiadas para el desembarco, lo cual ocurrió.

Los helicópteros llegaron, la tropa desembarcó hubo combates y allí murieron varios soldados. Los helicópteros despegaron para una segunda oleada la cual se cumplió.

Al ver que se estaban desembarcando y que ya les era difícil mantenerse en la población las FARC empezaron a evacuar el pueblo, saliendo por trochas, caminos y por el río Vaupés, las aeronaves de ala rotatoria y fija comenzaron a utilizar sus armas en contra de los guerrilleros que huían en desbandada y sorprendidos por la efectividad del poder aéreo. 
Con el plan concebido y ejecutado a la perfección por la Fuerza Aérea, se evitó lo que había sucedido en Miraflores, se recuperó Mitú en menos de dos días. Las FARC habían planeado permanecer allí varios meses, pero no contaron con la operación rápida de la Fuerza Pública. (Algo parecido a lo que sucedió en la Línea Maginot en la Segunda Guerra Mundial).

Mitú es un pueblo en la mitad de la selva, su calle principal es la pista aterrizaje, no había torre de control, era una pista de tierra, en esa pista aterrizó el Hércules. Esas eran las condiciones del terreno, pero la Fuerza Aérea Colombiana gracias a las ventajas del poder aéreo como la flexibilidad, la maniobrabilidad tiene las capacidades para cumplir con su misión. En esa pista como no había torre de control había un señor que era "el controlador aéreo" cuando iban a aterrizar los aviones, él salía con su carro y avisaba a la población. Hasta ahí fue mi participación en cuanto al planeamiento de la operación.

\section{CONCLUSIONES}

La Operación Vuelo de Ángel dejó grandes enseñanzas para la Fuerza Pública, especialmente para la Fuerza Aérea. Se aplicó la Doctrina Aérea que se tenía en el momento y sirvió de base para actualizar y mejorar dicha Doctrina, en la cual se realizaron las misiones típicas del Poder Aéreo con éxito.

Igualmente, se concluyó una vez más que el Poder Aéreo es definitivo en cualquier tipo de conflagración. El operar y dominar la tercera dimensión le da una ventaja a las propias tropas sobre el adversario. De ahí el slogan que acuño la Fuerza Aérea "nuestra presencia en el combate marca la diferencia".

La Operación Vuelo de Ángel marcó un hito en el desarrollo de los ataques terroristas de los grupos al margen de la ley. Al haber incursionado en la guerra de posiciones se le obligó a las FARC a regresar a la guerra de guerrillas. Mitú fue la última población que intentó tomarse y permanecer, el grupo terrorista.

Por otro lado, en esta Operación se utilizó y puso a prueba la última tecnología incorporada por la Fuerza Aérea como los visores nocturnos (NVG), el sistema FLIR (Forward looking infra-red), el perifoneo y los Tiradores de Precisión desde aeronaves (Teplas).

Estos nuevos elementos puestos al servicio de las operaciones, más el excelente entrenamiento y compromiso de nuestros pilotos y personal logístico permitió tener el éxito obtenido en la Operación Vuelo de Ángel y subsiguientes operaciones. Lo cual doblegó el espíritu de lucha de las FARC y los obligó a dialogar con el Gobierno.

La Operación Vuelo de Ángel permitió que el poder aéreo se potencializara en el conflicto armado interno. 
Pese a que con la toma de Mitú fuimos reactivos, las FFMM y en particular la Fuerza Aérea utilizaron satisfactoriamente sus capacidades militares con el objetivo de recuperar la capital del Vaupés. Así mismo, se demostró que las capacidades aéreas le permitían hacer presencia efectiva y controlar no solo el espacio aéreo sino también el territorio nacional, lo cual generó que se privilegiara y potencializara el poder aéreo en el conflicto armado interno colombiano.

Posteriormente, estas lecciones aprendidas fueron fundamentales para mejorar el modo de operar, se fortaleció y mejoró la Doctrina Aérea, pero quizá lo más importante fue que la Fuerza Aérea Colombiana se potencializó y se convirtió en una herramienta fundamental del Poder Nacional, para contrarrestar diferentes amenazas a la seguridad nacional.

Como lo señaló el presidente Andrés Pastrana, "tan solo habían transcurrido 90 días de gobierno y ya comenzaban a sentirse los primeros resultados de los cambios en la estrategia militar. Las Fuerzas habían adquirido una importante capacidad de reacción y la operación fue considerada como un modelo para otros ejércitos en el mundo, pues se demostró cómo se podían alcanzar objetivos esenciales con escasos recursos." (PASTRANA, 2005).

Por otro lado, gracias a las características del poder aéreo, la Operación Vuelo de Ángel es considerada como un punto de inflexión del conflicto armado colombiano:

"Igualmente, esta operación sirvió para que las FF.MM se dieran cuenta que el poder aéreo, es una ventaja que el Estado colombiano debe explotar al máximo, ya que el poder aéreo produce una asimetría que debe ser utilizada." (MARín et al, 2017).

Gracias a las capacidades aéreas en la Operación Vuelo de Ángel y el poder aéreo demostrado, esta operación ha sido reconocida por el Centro Nacional de Memoria Histórica, por su importancia estratégica. Al respecto en su informe "Tomas y Ataques guerrilleros" se estableció que "una medida fundamental para contener la avanzada guerrillera fue el fortalecimiento del poder aéreo, (...) El poder aéreo se convirtió para las FFMM (Fuerzas Militares) en una ventaja táctica que transformó la correlación de fuerzas entre el Estado y la guerrilla." (CNMH, 2017, p. 102).

Nuestra presencia en Mitú marcó la diferencia en el combate, la Fuerza Aérea Colombiana logró lo que en un principio parecía imposible para el Estado, revertir la estrategia armada de las FARC y gestar uno de los golpes más estratégicos contra el grupo ilegal de las FARC. Pese a una serie de dificultades geográficas, políticas, operacionales, la FAC logró maximizar su poderío aéreo y adaptarse a las condiciones en el teatro de operaciones, lo que género que hoy en día esta Institución cuente con altos y precisos procedimientos operacionales, así como la evolución doctrinaria que permitió que la FAC siempre esté a la vanguardia y respetuosa del Derecho Internacional Humanitario (DIH). 


\section{REFERENCIAS}

Capítulos de libro

CNMH. (2017). Tomas y ataques guerrilleros. Centro Nacional de Memoria Histórica. Bogotá.

MARÍN et al. (2017). La operacion Vuelo de Ángel: punto de inflexión del conflicto armado colombiano. En M. e. al, Victorias desde el aire: La Fuerza Aérea Colombiana y el término del conflicto armado colombiano. Bogotá: Editorial Ibáñez.

MARín et al. (2017). Reflexiones operacionales a partir de la experiencia de las tomas de Puerto Rico y Puerto Lleras. En M. e. al, Victorias desde el aire: La Fuerza Aérea Colombiana y el término del conflicto armado colombiano. Bogotá: Editorial Ibáñez.

PASTRANA. (2005). El día que cambio la guerra. En Pastrana, La palabra bajo fuego. Bogotá.

\section{Publicaciones Periódicas Académicas}

BeCERRA, O. D. (2016). Relaciones cívico-militares en Colombia: apuntes para un estado del arte. Revista Análisis Internacional(6).

Castilla, C. E. (2004). La Guerra por el Control Estratégico en el Suroccidente Colombiano. Revista Sociedad y Economía.(7), 65-89.

Santos, M., (2014).La Operación Vuelo de Ángel, el poder de la Fuerza Aérea Colombiana y el cambio en la asimetría de poder entre las FFMM y las FARC: Repositorio Universidad del Rosario Disponible en http://repository. urosario.edu.co/bitstream/ handle/10336/8913/1020765037-2014.pdf?sequence $=7$

Tokatlian, J. (2008). La Construcción De Un "Estado Fallido" En La Política Mundial: El caso de las relaciones entre Estados Unidos y Colombia. Análisis Político, 21(64), 67-104.

\section{Otros documentos}

DNP. (1991). Plan quinquenal para la fuerza pública 1992-1996. Obtenido de Departamento Nacional de Planeacion, Ministerio de Defensa Nacional.

LoBE (1998) Drogas y narcotráfico/ Estados Unidos: Certificación antidroga pierde partidarios. Disponible en http://www.ipsnoticias.net/1998/03/drogas-y-narcotrafico-estados-unidos-certificacion-antidroga-pierde-partidarios/

Fuerza Aérea Colombiana. (s.f.). Manual de Doctrina Aérea. 